\title{
Changes in the Thecal Vasculature During Follicular Atresia in the Ovary of Swamp Buffalo
}

\author{
Jun Babaan FERANIL ${ }^{1)}$, Naoki ISOBE ${ }^{1)}$ and Toshihiko NAKAO ${ }^{1) \#}$ \\ 1) Laboratory of Animal Science, Graduate School for International Development and \\ Cooperation, Hiroshima University, 1-5-1 Kagamiyama Higashi-Hiroshima 739-8529, Japan, \\ \#Present: Department of Veterinary Medicine, Faculty of Agriculture, Yamaguchi University, \\ Yoshida 1677-1, Yamaguchi 753-8515, Japan
}

\begin{abstract}
This study aimed to describe the changes in the thecal vasculature during ovarian follicular atresia in the swamp buffalo. Ovaries of Philippine swamp buffalo (Bubalus bubalis; SB), crossbred (SB $\times$ Murrah buffalo; CB) and Holstein-Friesian cow (Bos taurus; HF) were collected from slaughterhouses, fixed in $10 \%$ formalin in PBS and embedded in paraffin. Sections of healthy follicle and various follicular stages of atresia were stained with Bandeiraea simplicifolia-I lectin (BSL-I) to visualize the endothelial cells of blood vessels. In the theca interna, healthy follicles in SB had a significantly lower number of capillary vessels than other breeds and other atretic stages of follicle. From healthy to early atretic follicle, theca interna in all breeds showed a significant decrease in the area of capillary vessel. Capillary vessel area significantly increased (but was smaller than in healthy follicle) in the middle stage of atresia and declined again in the late atretic follicle (greater than in early atresia but smaller than in healthy follicle) in SB only. No significant change in the capillary vessel area of theca interna was noted in both CB and HF from early to late atretic follicles. There was no significant difference in the capillary vessel number and area of theca externa among the different breeds and atretic stages of follicle. These results suggest that there are dynamic changes occurring in the thecal vasculature of SB but not CB during follicular atresia which differs among cattle.
\end{abstract}

Key words: Endothelial cells, Follicular atresia, Lectin, Swamp buffalo, Theca interna

(J. Reprod. Dev. 50: 315-321, 2004)

E arlier reports have shown that a significant reduction in the capillary vasculature network of the theca interna occurs during follicular atresia in sheep [1, 2], pigs [2] and cattle [3]. The preovulatory follicles possess a larger capillary network than subordinate follicles [4]. Recently, it was reported that angiogenesis increases during bovine follicular growth and occurs unevenly in different inner theca regions [5]. These studies exemplified the relationship between the alterations in the thecal vasculature distribution and follicular development or atresia. However,

Accepted for publication: February 12, 2004

Correspondence: N. Isobe (e-mail: niso@hiroshima-u.ac.jp) there is no available information in the literature about the thecal vasculature network of the swamp buffalo (SB) ovary.

Bandeiraea simplicifolia-I (BSL-I, binding specificity: $\alpha-N$-acetylgalactosamine and $\alpha$ galactose), one of the lectins (specific carbohydratebinding proteins of non-immune origin), has proven utility for visualization of blood vessels [6, 7]. The vasculature in the theca layer surrounding follicles was visualized by BSL-I in pig [6].

The aim of the present work was to describe the quantitative changes in the vascular network of the theca layer during follicular atresia in the swamp buffalo by using BSL-I lectin. 


\section{Materials and Methods}

\section{Collection and preparation of tissues}

Ovaries from healthy, non-pregnant Philippine SB (Bubalus bubalis, number of animals $=15$ ) and crossbreds between SB and Murrah buffalo (CB; number of animals $=9$ ) were collected at a slaughterhouse in Manila, Philippines. Ovaries were also collected from Holstein-Friesian cows (Bos taurus, HF; number of animals $=10$ ) at slaughterhouses in Onomichi and Hiroshima cities. The age and body condition score of SB and CB ranged between 5 and 9 years old, and 2 and 4 years old, respectively (Table 1 ). The age was determined by dental examination [8]. The mean live weights of SB and CB were 411 and $539 \mathrm{~kg}$, respectively. Heartgirth measurements were used for the determination of live weight in SB and CB. Both left and right ovaries were collected from each animal. Blood samples were also collected via the external jugular vein from SB and CB before slaughter for determination of plasma progesterone levels to assess whether the animals were in the luteal phase or not. Plasma concentrations of progesterone were estimated by enzyme immunoassay [9]. No macroscopic abnormality was observed in the reproductive tracts of animals. Ovaries were immediately fixed in $10 \%$ formalin in PBS and processed for paraffin sections (5 $\mu \mathrm{m}$ thick) which were air dried on slides treated with 3aminopropyltriethoxysilane (Sigma Chemical Co., St. Louis, MO, USA) as previously described [10].

\section{Lectin histochemistry}

After deparaffinization with xylene, the sections were rehydrated through a series of graded volumes of ethanol in distilled water $(100,95,90$, 80 , and $70 \%$ ), washed in PBS (5 $\mathrm{min}$ ) and incubated with $20 \mu \mathrm{g} / \mathrm{ml}$ proteinase K (Sigma) in $10 \mathrm{mM}$ Tris$\mathrm{HCl}, \mathrm{pH} 7.4$ at $35 \mathrm{C}$ for $20 \mathrm{~min}$ in a humidified chamber, then with $10 \mu \mathrm{g} / \mathrm{ml}$ biotinylated Bandeiraea simplicifolia-I (BSL-I; Sigma) at 35 C

Table 1. The age, liveweight, body condition score, and plasma progesterone concentration of the swamp buffalo and crossbred (swamp buffalo $\times$ Murrah buffalo)

\begin{tabular}{ccccc}
\hline Breed & $\begin{array}{c}\text { Age }^{\mathrm{a}} \\
\text { (years) }\end{array}$ & $\begin{array}{c}\text { Liveweight }^{\mathrm{b}} \\
(\mathrm{kg})\end{array}$ & $\begin{array}{c}\text { Body condition } \\
\text { score }^{\mathrm{c}}\end{array}$ & $\begin{array}{c}\text { Progesterone } \\
\text { level (ng/ml) }\end{array}$ \\
\hline Philippine swamp buffalo (SB) & 8 & 552 & 4 & 0.70 \\
& 8 & 502 & 3 & 3.75 \\
& 8 & 465 & 3 & 4.90 \\
& 9 & 512 & 3 & 8.50 \\
& 6 & 436 & 3 & 1.70 \\
& 7 & 436 & 3 & 0.01 \\
& 8 & 521 & 3 & 5.50 \\
& 7 & 540 & 3 & 0.60 \\
& 7 & 446 & 3 & 3.25 \\
& 7 & 455 & 2 & 0.02 \\
& 7 & 521 & 3 & 3.20 \\
& 5 & 455 & 3 & 3.50 \\
& 6 & 436 & 3 & 1.30 \\
& 6 & 417 & 3 & 2.00 \\
& 7 & 446 & 3 & 3.40 \\
& 9 & 552 & 3 & 0.48 \\
& 7 & 542 & 3 & 0.02 \\
& 8 & 562 & 3 & 7.00 \\
& 8 & 621 & 4 & 4.00 \\
& 8 & 516 & 3 & 4.63 \\
& 6 & 522 & 3 & 0.73 \\
& 6 & 542 & 3 & 0.16 \\
\hline
\end{tabular}

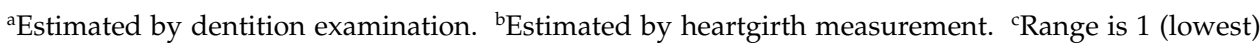

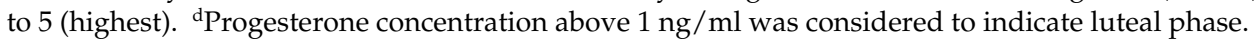


overnight in a humidified chamber. After washing with PBS for $8 \mathrm{~min}(4 \mathrm{~min} \times 2)$, the lectin binding was detected by using Vectastain ABC-PO kit (Vector Laboratories Inc., Burlingame, CA, USA) according to the manufacturer's protocol. Briefly, the sections were incubated with avidin and biotin peroxidase complex for $1 \mathrm{~h}$. Lectin binding was visualized by incubating the sections with a substrate solution consisting of $2 \mathrm{mg} \mathrm{3'}, 3^{\prime}$ diaminobenzidine and $10 \mu \mathrm{l} 5 \% \mathrm{H}_{2} \mathrm{O}_{2}$ in $10 \mathrm{ml} 0.05$ $\mathrm{M}$ Tris- $\mathrm{HCl}(\mathrm{pH} 7.5)$ for $15-60 \mathrm{sec}$, and then counterstained with hematoxylin for $15 \mathrm{sec}$. To determine the specificity of lectin binding, staining of negative control was carried out by incubating a section with lectin that was preincubated with 0.4 $\mathrm{mol} / 1$ galactose for $2 \mathrm{~h}$ [11].

\section{Classification of follicles}

Follicles were histologically classified into healthy, early atretic, middle atretic and late atretic. Healthy follicles had an intact and well-arranged granulosa layer. Atretic follicles were classified based on the criteria described by Hay et al. [1]. Early atretic follicles had a minimal number of pyknotic cells, degenerated cells and/or apoptotic bodies distributed along the antral border of the granulosa layer. Middle atretic follicles contained numerous pyknotic cells, degenerated cells and/or apoptotic bodies in the granulosa layer, while in the late atretic follicle the granulosa cells were already phagocytized by leukocytes leading to disappearance of the granulosa layer. The numbers of follicles examined were 4, 6, 9 (healthy), 5, 5, 5 (early atretic), 5, 5, 6 (middle atretic) and 9, 12, 6 (late atretic) in SB, CB and $\mathrm{HF}$, respectively.

\section{Analysis of lectin-positive capillary vessels}

Three sections per ovary (approximately $2 \mathrm{~mm}$ apart from each other) were examined. All available follicles with a diameter of $\geq 3 \mathrm{~mm}$ at the largest cross-sectional area were included in the analysis. Observation was conducted in 5 equidistant areas of theca layer in each follicle (approximately 10,000 to $50,000 \mu \mathrm{m}^{2}$ ). Lectin binding of capillary vessels was counted using an image analyzer with a computer system (Mac Aspect, Mitani Co., Fukui, Japan). The area of capillary vessel contained both endothelial cells and lumen of vessel. The capillary vessel number and capillary vessel area in the theca interna and externa were expressed as values per $20,000 \mu \mathrm{m}^{2}$ area. The number and area in a follicle was expressed as the average of 5 counts.

\section{Statistical analysis}

Differences in the capillary vessel number and area among different breeds as well as among different follicular stages of atresia were analyzed by two-factor ANOVA, followed by Duncan's multiple range test. Differences were considered to be significant at $\mathrm{P}<0.05$.

\section{Results}

All endothelial cells of blood vessels were bound to the lectin in the theca interna and externa in all stages of atresia of all breeds (Fig. 1). A welldeveloped capillary network was observed in the theca interna mainly adjacent to the basal lamina of healthy follicles and a slightly poor network of capillary was observed in the theca interna of atretic follicles.

Plasma progesterone concentrations varied between 0.01 and $8.50 \mathrm{ng} / \mathrm{ml}$ in SB and 0.02 and $7.00 \mathrm{ng} / \mathrm{ml}$ in CB (Table 1). Percentages of animals showing progesterone concentrations $1.0 \mathrm{ng} / \mathrm{ml}$ or above indicating the presence of functional corpus luteum were $73.3 \%$ in SB and $55.6 \%$ in $C B$, respectively. However, the comparison of capillary vessel distribution between those in luteal and nonluteal phase was not made due to the limited number of follicles examined.

In the theca interna, there was no significant difference in the number of capillary vessels among the different breeds as well as among the follicular stages of atresia (Fig. 2A). Nevertheless, a significant breed-by-follicle interaction was noted in the number of capillary vessels; healthy follicles of SB had a significantly lower capillary vessel number. There was a significant decrease in the area of the capillary vessel of theca interna towards early atresia in SB, CB and HF (Fig. 2B). In SB, there was an initial decrease towards early atresia followed by an increase in the middle atretic follicles and reduction again in the late atretic follicles. However, capillary vessel area remained low in CB and HF from early atresia and thereafter. In addition, a low and non-significant correlation coefficient was noted between the capillary vessel numbers and capillary vessel areas in theca interna $\left(r^{2}=0.305\right)$. 

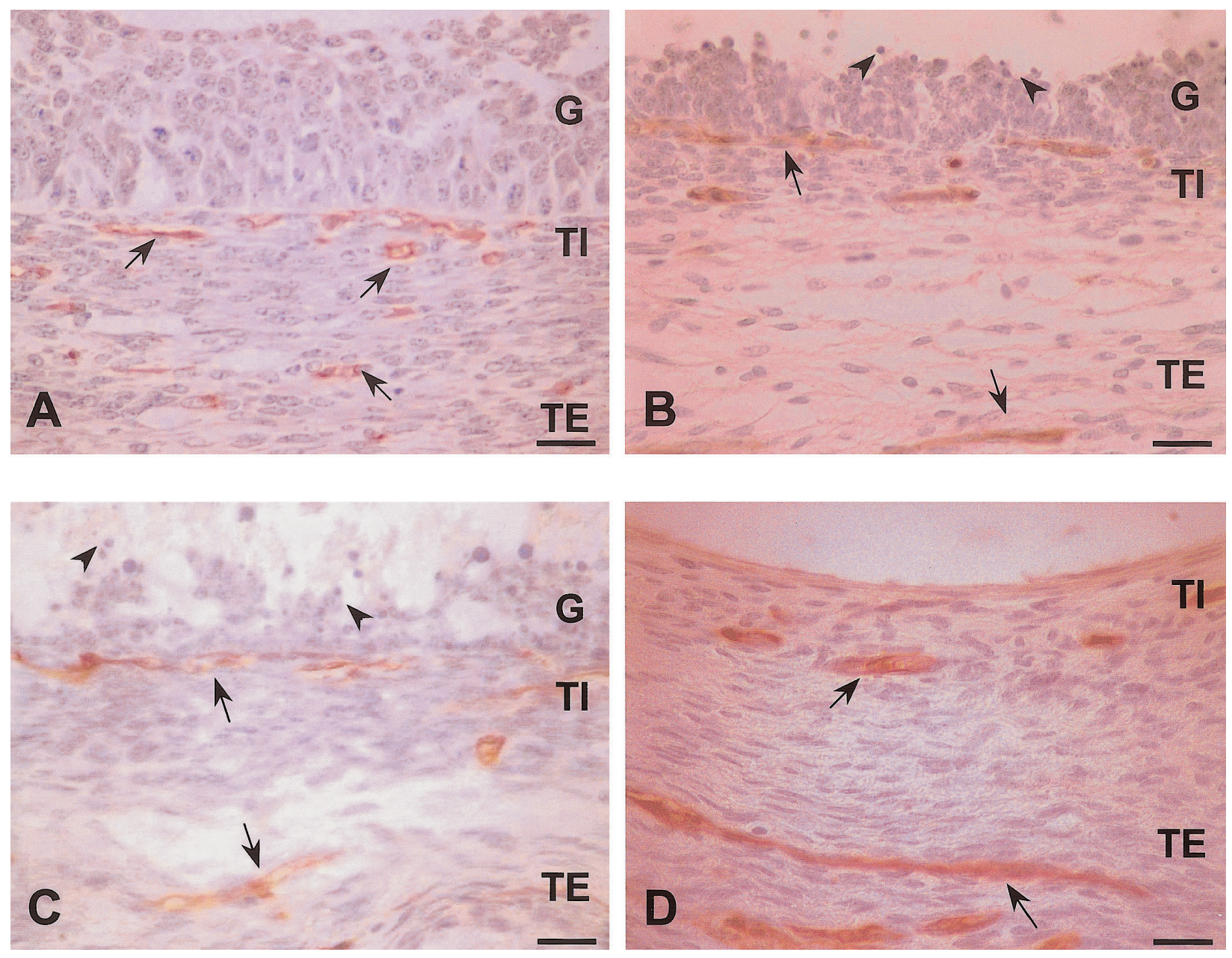

Fig. 1. Light micrographs of the swamp buffalo healthy antral follicle (A), early atretic follicle (B), middle atretic follicle (C) and late atretic follicle (D) stained with lectin (BSL-I). Arrows indicate lectin-binding capillary vessels, and arrowheads show apoptotic bodies and/or pyknotic cells. G: granulosa layer; TI: theca interna; TE: theca externa. Bars $=10 \mu \mathrm{m}$.

In the theca externa, a markedly high capillary vessel number was noted in the middle atretic follicles of HF and late atretic follicles of $\mathrm{CB}$, although there was no significant difference among breeds, follicular stages of atresia and in the breedfollicle type interaction (Fig. 2C). Similarly, differences in capillary vessel area were not significant among the breeds and follicular stages of atresia (Fig. 2D). The capillary vessel areas were lower in the theca externa than interna. Similar to the theca interna, there was a low correlation coefficient $\left(r^{2}=0.337\right)$ between capillary vessel numbers and areas in the theca externa.

\section{Discussion}

The present study provides a first description of the changes in the density of thecal vasculature of SB during follicular atresia by localization of lectin (BSL-I). The significant findings were: (a) the healthy follicle had a significantly lower capillary vessel number than other breeds and follicular stages of atresia; (b) the capillary vessel area decreased from healthy to early atretic follicles, increased in the middle stage of atresia followed by reduction towards late stage of atresia; and (c) low correlation coefficients were established between capillary vessel numbers and areas in both theca interna and externa. 


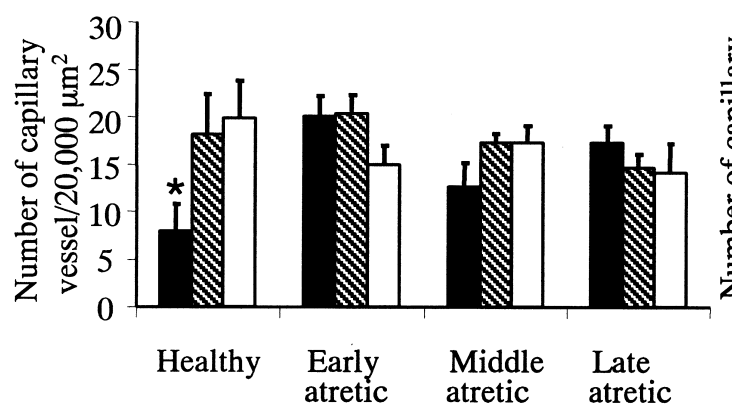

A

Follicular stages of atresia

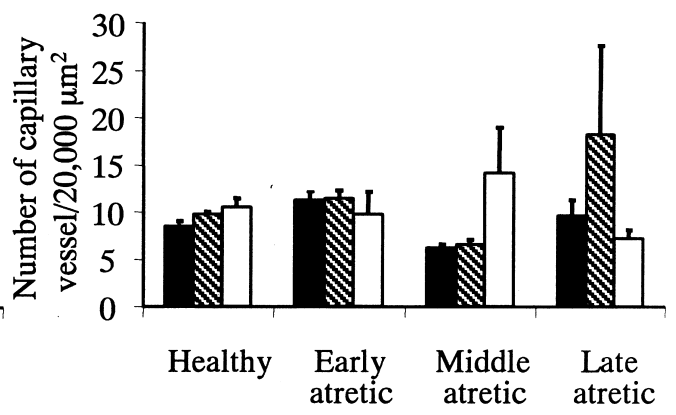

C Follicular stages of atresia
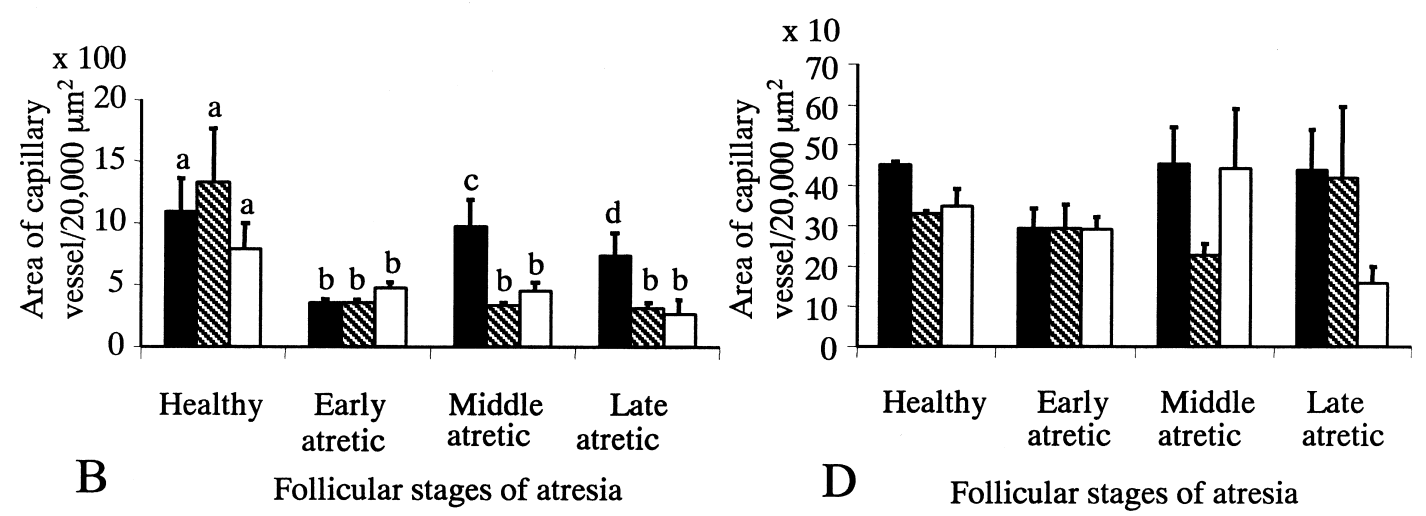

Fig. 2. Number $(A, C)$ and area $(B, D)$ of capillary vessels in the theca interna $(A, B)$ and externa $(C, D)$ of various follicular stages of atresia. Bars represent the mean \pm SE. The closed, striped and open bars represent swamp buffalo, crossbred and Holstein-Friesian cow, respectively. Values with different letters between follicular stages of atresia $(\mathrm{a}, \mathrm{b}, \mathrm{c})$ are significantly different $(\mathrm{P}<0.05)$. Asterisk $\left(^{*}\right)$ represents a significant breed $\times$ follicle interaction $(\mathrm{P}<0.05)$.

In $\mathrm{SB}, \mathrm{CB}$ and $\mathrm{HF}$, capillary vessel areas in the theca interna of all types of atretic follicles were significantly lower than in healthy follicles. This suggests that the process of follicular atresia is associated with the quantitative changes of blood vessels in the theca interna of the buffalo as well as the cow. This is in agreement with reports on other species of animal $[1-3,12]$. Additionally, scanning electron microscopy studies of ovarian follicle corrosion casts of various animals revealed similar observations [5, 13-17]. Thus, these findings support the concept that follicular atresia is accompanied by significant thecal capillary structural changes [18].

Healthy follicles in SB had a significantly lower capillary vessel number in the theca interna compared to the other follicular stages of atresia and breeds. Since a developed capillary vessel network is necessary for follicular growth $[1,5]$, this lower number of capillary vessel might be related to weakened follicular activity in SB.

The changes in the capillary vessel area during atresia were different in SB from the other two breeds. Only SB showed a marked increase of capillary vessel area in the theca interna of middle atretic follicles. This temporal increase in the capillary vessel area may be associated with the delay of the atretic process in the swamp buffalo. However, a previous observation of ours revealed that no apparent rise was detected in the cell proliferation of theca interna in the swamp buffalo (unpublished data). Hence, the precise mechanism of the temporal increase in capillary vessel area of the middle atretic follicle of the swamp buffalo is 
unclear.

All animals examined showed a higher capillary vessel area of theca interna than externa. This might be attributable to the increased complexity of vascular plexuses particularly in the theca interna, as shown by electron microscopy of ovarian tissues [19] and vascular corrosion casts in various animals $[5,15,20]$.

The present work also showed a low correlation coefficient between the capillary vessel number and area in the theca interna, indicating that number and area of the thecal vasculature are not dependent on each other. Blood vessels have been reported to be formed by different mechanisms of increasing lumen caliber. According to Drake and Little [21], the relevant cell biological mechanisms of blood vessel are replication (cell division), hypertrophy, increased degree of cell spreading behavior and recently, vascular fusion of endothelial cells. Taken altogether, the changes in the capillary vessel number and area in the follicle may occur due to different biological mechanisms in the different stages of follicular atresia.

No significant difference was detected in the capillary vessel number and area of the theca externa among the different breeds in this study. This may indicate that the vasculature in the theca externa is not affected during follicular atresia in the swamp buffalo as well as in cattle.

In conclusion, the current study showed that in $\mathrm{SB}$, the number of capillary vessels in the theca interna is significantly low in healthy follicles suggesting a distinct vasculature pattern, and that the capillary vessel area in the theca interna decreased from healthy to early atretic follicles and increased again in the middle atretic follicles.

\section{Acknowledgements}

The first author is greatly indebted to the Ministry of Education, Culture, Sports, Science and Technology (Monbukagakusho), Government of Japan, for the scholarship granted for pursuing this research work and to the Cavite State University, Philippines for logistical support during specimen collection.

\section{References}

1. Hay MF, Cran DG, Moor RM. Structural changes occurring during atresia in sheep ovarian follicles. Cell Tissue Res 1976; 169: 515-529.

2. Cran DG, Osborn JC, Rushton D. Thecal vasculature and oocyte maturation during follicular atresia in the sheep and pig. Reprod Nutr Dev 1983; 23: 285-292.

3. Marion GB, Gier HT, Choudary JB. Micromorphology of the bovine ovarian follicular system. J Anim Sci 1968; 27: 451-465.

4. Shimizu T, Jiang JY, Sasada H, Sato E. Changes of mRNA expression of angiogenic factors and related receptors during follicular development in gilts. Biol Reprod 2002; 67: 1846-1852.

5. Jiang JY, Macchiarelli G, Tsang BK, Sato E. Capillary angiogenesis and degeneration in bovine ovarian antral follicles. Reproduction 2003; 125: 211223.

6. Plendl J, Neumuller C, Vollmar A, Auerbach R, Sinowatz $\mathbf{F}$. Isolation and characterization of endothelial cells from different organs of fetal pigs. Anat Embryol 1996; 194: 445-456.

7. Jilani SM, Murphy TJ, Thai SNM, Eichmann A, Alva JA, Iruela-Arispe M. Selective binding of lectins to embryonic chicken vasculature. J
Histochem Cytochem 2003; 51: 597-604.

8. Maala CP, Domingo $\mathbf{R}$, Ducusin RJ. The anatomy of the temporary and permanent incisors of the carabao (Bubalus bubalis). Phil J Vet Med 1988; 25: 714.

9. Isobe $\mathbf{N}, \mathbf{N a k a o} \mathbf{T}$. Direct enzyme immunoassay of progesterone in bovine plasma. Anim Sci J 2003; 74: 369-373.

10. Isobe N, Yoshimura Y. Immunocytochemical study of cell proliferation in the cystic ovarian follicles in cows. Theriogenology 2000; 54: 1159-1169.

11. Augustin HG, Braun K, Telemenakis I, Modlich U, Kuhn W. Phenotypic characterization of endothelial cells in a physiological model of blood vessel growth and regression. Am J Pathol 1995; 147: 339351.

12. Zeleznik AJ, Schuler HM, Reichert LE Jr. Gonadotropin-binding sites in the Rhesus monkey ovary: role of the vasculature in the selective distribution of human chorionic gonadotropin to the preovulatory follicle. Endocrinology 1989; 109: 356362.

13. Ginther OJ, Del Campo CH. Vascular anatomy of the uterus and ovaries and the unilateral luteolytic effect of the uterus: cattle. Am J Vet Res 1974; 35: 193 
203.

14. Lamond DR, Drost M. Blood supply to the bovine ovary. J Anim Sci 1974; 38: 106-112.

15. Macchiarelli G, Nottola SA, Vizza E, Familiari G, Kikuta A, Murakami T, Motta PM. Microvasculature of growing and atretic follicles in the rabbit ovary: a SEM study of corrosion casts. Arch Histol Cytol 1993; 56: 1-12.

16. Yamada $\mathrm{O}$, Abe $\mathbf{M}$, Takehana $\mathrm{K}$, Iwasa $\mathrm{K}$, Hiraga $T$, Hiratsuka T. Microvasculature of mature bovine follicles and its changes with ovulation. J Reprod Dev 1994; 40: 307-315.

17. Yamada $\mathbf{O}$, Abe $\mathbf{M}$, Takehana $\mathrm{K}$, Hiraga $\mathrm{T}$, Iwasa K, Hiratsuka T. Microvascular changes during the development of follicles in bovine ovaries: a study of corrosion casts by scanning electron microscopy. Arch Histol Cytol 1995; 58: 567-574.

18. Macchiarelli G. The microvasculature of the ovary: a review by SEM of vascular corrosion casts. J Reprod Dev 2000; 46: 207-225.

19. O'Shea JD, Hay MF, Cran DG. Ultrastructural changes in the theca interna during follicular atresia in sheep. J Reprod Fert 1978; 54: 183-187

20. Jiang JY, Macchiarelli G, Miyabashi K, Sato E. Follicular microvasculature in the porcine ovary. Cell Tissue Res 2002; 310: 93-101.

21. Drake CJ, Little CD. VEGF and vascular fusion: implications for normal and pathological vessels. $J$ Histochem Cytochem 1999; 47: 1351-1355. 